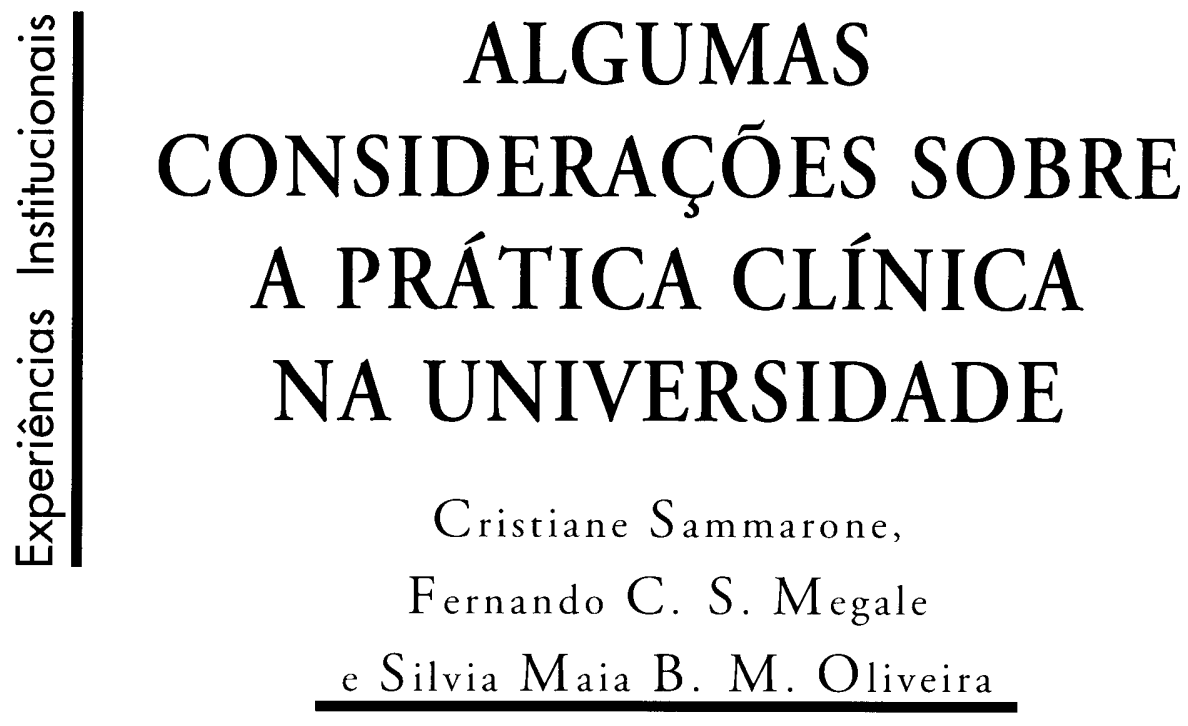

(1)

presente trabalho tem como objetivo percorrer algumas questòes que se impòem quando falamos da Psicanálise inserida na universidade. Três eixos básicos estào em jogo e se colocam permanentemente como pontos de reflexào e discussào. Estamos falando da Psicanálise, da formaçào na universidade e do atendimento à clientes em uma instituiçào de ensino.

O primeiro eixo indica o lugar da Psicanálise na questão do ensino universitário e que tipo de inserçào é possivel e desejável que se tenha. Produzse, com efeito, uma mudança do campo clínico, na medida em que passa-se a

pensar a Psicanálise fora do âmbito tradicional, qual seja, o consultório particular e o trabalho individual. Nesse caminho, a Psicanálise passa a sofrer reconstruçòes em sua origem e em seu lugar "confortável", para se deparar com outros elementos. Aqui falamos da instituiçào e da cultura que permeiam essa "reconstruçào".

O segundo eixo nos fala, ao mesmo tempo, de um processo de formaçào curricular, permeado pela relaçào professor-aluno, supervisor-aluno, e de um espaço mobilizado inexoravelmente pelo discurso do mestre. E, sabemos, que há, entre o discurso ana-

Psicanalista; mestranda em Psicologia Clínica na Pontifícia Universidade Católica de São Paulo; professora da Universidade São Judas Tadeu. - Psicanalista; mestre em Psicologia Escolar pela Universidade de São Paulo; professor da Universidade São Judas Tadeu. -1 Psicanalista; mestranda em Psicologia Clínica na Pontifícia Universidade Católica de São Paulo; professora da Universidade São Judas Tadeu. 
lítico e o discurso do mestre, oposiçoes, embates e contradiçoes.

O terceiro eixo fala, sobretudo, da clientela que demanda algum tipo de atendimento à instituiçào e as implicaçoes culturais e de linguagem que batem à porta desta instituiçào. Estamos diante de contextos culturais e sociais diferentes entre si e complexos em suas peculiaridades.

O trabalho ao qual nos referimos, acontece no Centro de Psicologia Aplicada (CPA), que funciona como clínica-escola do curso de Psicologia da Universidade Sào Judas Tadeu, onde sào realizados atendimentos voltados principalmente para a comunidade da Zona leste de Sào Paulo.

Descle o início, nossa proposta foi alvo de muita reflexão, mudanças e, portanto, movimento. Sempre nos questionamos como faríamos isso, onde nos apoiaríamos para poder "ensinar" algo aos nossos alunos. A nós, se apresentava como uma idéia nova. Temos uma formaçào em P’sicanálise e estamos habituados a trabalhar com um modelo tradicional, dentro de um determinado setting, sem um tempo específico para o término do tratamento. Na realidade, só tínhamos um caminho: refletir solbre a prática com a qual nos deparávamos.

O nosso trabalho é de diagnóstico, porém, nào se limita apenas a esse objetivo. Partimos de uma crítica a um modelo clássico de formaçà, onde o psicodiagnóstico é visto, muitas vezes, apenas como um processo intermediário e via de acesso a uma psicoterapia, como propòe Ocampo (1981) e mais recentemente Arzeno (1995), em seus respectivos trabalhos sobre o assunto. Essas autoras tiveram um papel importante ao analisar o processo psicodiagnóstico sob a luz da Psicanálise. Introduziram um pensar psicanalítico em um processo que, até então, se limitava quase a um exercício técnico, porém, caracterizaram o psicodiagnóstico, como uma prática bastante "estreita", com o principal objetivo de investigaçào. Segundo Ocampo, o processo visa conseguir uma descriçà) e compreensào o mais profunda e completa possivel da personalidade do paciente ou do grupo familiar, e que uma vez atingido esse objetivo, caberia ao profissional formular um diagnóstico e por fím uma indicaçào clínica.

O que percebemos é que esse modelo tradicional passa a nào responder àquilo que ocorre durante o processo. O trabalho proposto realiza-se em, aproximadamente, doze sessoes. Na maioria dos casos, recebemos um grupo familiar que se apresenta em torno de uma "queixa", mas nossa escuta visa percorrer de forma mais ampla e rica a demanda em questão. Em grande parte dos atendimentos, optamos por um trabalho paralelo onde pais e crianças sào atendidos sem interrupçoes ao longo do processo, não simplesmente concentrando o trabalho de devoluçào nas últimas entrevistas. É um trabalho que se propòe interventivo desde o início e requer uma postura mais ativa de ambas as partes.

O trabalho procura escutar esse cliente que nos chega, com 
sua demanda e procluzir efeitos de deslocamento nessa mesma demanda que, inicialmente, pode aparecer comos um pedido muito específico ou aprisionado em uma certa imagem de que o) estagiário-terapeuta terá uma resposta ou um saber estabelecido a priori. Nessa indicaçào clínica proposta, isto é. recolocá-lo frente a sua própria demanda, tenta-se promover algo da ordem da mudança. Mas que mudança é essa?

Isso significa estarmos, enquanto supervisores, experimentando o que pensamos ser uma outra forma de trabalho com o aluno e. consequentemente, com o cliente, que nào visa a climinaçào de sintomas mas sim um posicionamento perante às questoes e a) sofrimento que a doença coloca. Portanto, frente à dor e ao désespero de uma criança e seus pais (e mesmo professores, médicos ou qualquer outro que tem seu narcisismo abalado por aquele que fallha, que nào responde adequadamente e que nos remete à imagem nào ideal de nós mesmos mas sim, à uma imagem fraturada pela inserça de uma falta ou de uma insuficiência de funcionamento), convidamoos a que falem mais. Isto é. frente ao sofrimento do outro que nos demanda a cura, respondemos com um "Porque nào sei sobre seu sofrimento, é preciso que você fale".

Nesse senticlo, o que se produz nesse espaco, forjado entre o estagiárioterapeuta e o/os clientes. provoca, no mínimo, uma rotaçào de posiçào que recupera ce outorga importância a um saber próprio dos clientes, antes marginalizado, desacreditado e. muitas vezes, nomeado como patológico. Mesmo, em diversos clientes que nos chegam, oncle, por ve'zes, os referenciais organizadores de sua vida nào parecem indicar um sentido para a mesma, as intervençoes tentam reconstruir e produzir um lugar de sujeito reconhecido em sua dimensão desejante e, por que nào, de cicladìo.

Em um certo sentido, trata-se de um processo similar à chamadas Entrevistas Preliminares, já que nestas também há um movimento de deslocamento da demanda e da desalienação de sua fala. Como diz Mannoni (1981): "Estamos em presença de um discurso quer se trate do discurso dos pais ou dacquele do filho - que se pode qualificar "de alienado", no sentido etimológico do vocábulo - em vez de mentiroso, como somos tentados a dizer por imagem, já que ele nào é o discurso do sujeito, mas clos outros, ou dà opiniào."

As intervençoes, mesmo sendo um trabalho com delimitaçào de tempo, nào se encaminham em uma suposta imagem de adequaçào social do cliente ou cm um desejo de harmonizaçào e felicidade, recusando a dimensão do conflito, das interrogaçoes e das incongruêncials da ordem do humano. A escuta permite reconsiderar os recursos e potencialidades do cliente, assegurando-the um lugar de sujeito, entretanto, movimentando os sentidos e versòes faladas e reinventadas na relaçào com o estagiário-terapeuta. Os "resultados" indicam mais um repensar do cliente sobre suas relaçoes, sobre si-próprio e sobre as questoes que trouxe do que uma suposta eficiência imagrinária, no estilo de: "descobrimos o que você tem. ou o que acontece com você é...".

Entretanto, sabe-se das armadilhas e dos fortes apelos que o apaziguar, o harmonizar, que uma tentativa de restabelecer o bem-estar psífuico, colocamse para aquele que está frente à alguém sumamente angustiado e desesperado. É grande () ganho narcísico para um estagiário, que comeca a tomar contato com a clínica, ver seu cliente frente ao "nada quero saber solbre o que me faz sofier, apenas quero ser curado" e ter, 
surpreenclentemente, ao longo de alguns encontros, seu sofrimento aplacado ou mesmo um sintoma desaparecido abrir mào do lugar de conivência com esses efeitos terapêuticos que o escutar um outro, no mais das vezes, proporciona. Entretanto, como supervisores, é preciso que estejamos sempre a postos para sinalizar que esse é um mau lugar: confortável para cliente e terapeuta, mas um lugar equivocado.

Em verdade, essa parece se constituir uma das maiores dificuldades da prática de supervisào: fazer ver que aplacar, sugerir, orientar, dar respostas, tranqüilizar pode conduzir a uma alienaçào sintomática ainda maior e provavelmente um sofrimento ainda mais nefasto. Entrando em um lugar de maestria, impondo um conhecimento educativo sobre os clientes, induziríamos a mais uma alienaçào ou a mais um nome ou doença.

É interessante que para um aluno que chega para seus primeiros encontros com um paciente supondo nada saber e constrangido, muitas vezes, com a obrigatoriedade de um currículo que the diz em determinado momento: "Agora, pronto ou não, disponha-se a ouvir pessoas que sofrem psiquicamente", cle descobre muito surpreso e grato, que há um algo (a transferência) que o constitui, ainda que no mais das vezes ele recuse e resista, nesse lugar suposto de saber sobre um sofrimento e descle onde the é endereçada uma demanda de cura. Fica perplexo (e com razào) que tal qual na teoria, já havia sido previsto, que essa tal transferência se instala e produz seus efeitos pelo simples fato dele estar ali à disposiçào de ouvir. No entanto, muitas vezes, por nào ter podiclo fazer ele mesmo a experiência do inconsciente, ficam tomados nas malhas transferenciais, respondendo identificados aos lugares que o discurso dos clientes os colocam.
É preciso muita paciência, delicadeza e firmeza para poder apontar a um aluno que no lugar onde as entrevistas "derrapam", nào há técnica, sugestào ou conselho a ser seguido que possa reconduzir as coisas pelo "bom" caminho. Que, nesse momento, já não é mais do cliente que se fala, mas sim do cliente que ele forjou de acordo com seus pontos fantasmáticos implicados $\mathrm{e}$ sobre os quais é necessário lançar luz, desfazer certezas. Geralmente, é no próprio espaço de supervisão que uma certa transferência se joga e que é endereçada ao supervisor uma demanda de "restabeleça a ordem do atendimento, faça-me não sofrer com essa experiência de ignorância necessária ao desalienar do outro que me torna com interlocutor de seu sofrimento". Frente a ela, o que faz o supervisor? Indica técnicas, oferece receitas e conselhos? Sim, se quiser fazer de seu supervisionando sua imagem e semelhança, que the devolva uma imagem acabada de potencia frente à experiência de impossibilidade de engano que é tratar claquilo que resiste a ser tratado, isto é, um sintoma. Ou entào, se cala, e convida ao outro que fale ainda mais sabendo-se implicado nessa fala que lhe é dirigida e que the pergunta sobre a eficácia da palavra para tratar dos males da alma.

É possivel que nessa leitura se pense que isso se dá o tempo inteiro. Entretanto, são, quem sabe, em alguns momentos privilegiados que isso realmente acontece.

Desde estas consideraçoes que fizemos e com caráter de conclusào, arriscamos dizer que há uma dimensào de cidaclania (e por que nào dos alunos e nossa também) que passa por esse desassujeitamento em relaça a tantos outros que nomearam o cliente das mais diferentes formas: um corpo doente, uma mente doente, uma màe nào tào boa, um pai ausente, uma família 
desestruturada etc. Recontar sua história é, muitas vezes, livrar-se desse "recheio indigesto" patológico, reassumindo uma outra posição, posicionando-se diante destes outros. Isto não quer dizer parar de tomar medicaçào em alguns casos, por exemplo, mas interrogar-se e ao outro do sentido desse procedimento. Concordamos com Costa (1989) quando afirma que "não existe doença independente de seu modo de expressão. A idéia de causalidade faz parte da maneira como a doença se constrói. A representação da causalidade é indissociável da subjetividade que a produz".

Procuramos, com estas indicaçòes, refazer o caminho de construçào do sintoma, de suas vertentes que o sustentam, reiterando, como nos diz Freud, os sentidos desses sintomas nas experiências dos clientes. Tentamos garantir aquilo que se apresenta como a questào fundamental ao falarmos da clínica da Psicanálise, ou seja, a escuta. Escuta que perpassa a clientela e suas diferenças culturais, sobrevoa o espaço de supervisão marcado por suas contradições e retorna à experiência que se constrói na relação entre o estagiário-terapeuta e os clientes. Constitui-se um tipo de formação que pretende implicar os que a produzem em suas práticas e em suas açòes, sejam os professores-supervisores, sejam os alunos-terapeutas, sejam os clientes-cidadãos.

\section{REFERENNCIAS BIBLIOGRÁFICAS}

MANNONI, M. (1981). A primeira entrevista em psicanálise. Rio de Janeiro: Campus.

ANCONA-LOPEZ, M. (org.). (1994). Psicodiagnóstico: processo de intervençào. Sào Paulo: Cortez, 1995.

COSTA, J. F. (1989). Psicanálise e contexto cultural: imaginário psicanalitico, grupos e psicoterapias. Rio de Janeiro: Campus.

OCAMPO, M. L. S. (1989). Oprocesso psicodiagnóstico e as técnicas projetivas. Sào Paulo: Martins Fontes.

ARZENO, M. E. G. (1995). Psicodiagnóstico clínico, novas contribuiçoes. Porto Alegre: Artes Médicas.

MILLER, J. - A . (1997). Psicoterapia e psicanálise, in Forbes, J. ( org.) Psicanálise ou psicoterapia, Campinas: Papirus. 